\title{
Student Perspectives Of Competition: A Qualitative Analysis
}

Michael W. Firmin, Ph.D., Cedarville University, USA

Jennifer Evens Lucius, M.Ed., University of Georgia, USA

Sharon Johnson, D.B.A., Charleston Southern University, USA

\begin{abstract}
The present study involved action research of appraising business students' individual assessments of a classroom competition exercise in which they participated for a university semester. Analysis of in-depth interviews held with each student show four over-arching themes shared by the participants. First, students showed significant self-insight into how they perceive themselves competing. This occurred on both the cognitive and affective domains. Second, with relative consistency, students reported avoiding competitive situations where they did not believe chances were good that they would win. Conversely, they tended to involve themselves in situations where success was perceived as possible or likely. Third, gender differences existed in how the students viewed competition. And fourth, we found that classroom competition affected how the students related to one another on personal levels.
\end{abstract}

Keywords: Competition, business education, qualitative research

\section{INTRODUCTION}

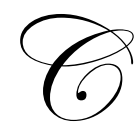

ompetition is embedded into the fabric of American society. Given the historic tradition of capitalism in the United States, combined with an emphasis on sporting events, competition simply is an assumed part of culture. How does this fact relate, therefore, when students enter classrooms? Do they expect competition to be part of the classroom or does education have a pass from the normal expectations of our competitive society?

For certain educational fields, competition is enmeshed into the curriculum. Physical education is the obvious example (Singleton, 2003). It would be difficult to take an entire course that daily involves games and not expect some level of competing where someone wins and others lose. Students leave physical education classes being affected, to some level, by the results of these competitions (Adie, Duda, \& Ntoumanis, 2008). The arts, similarly, have longstanding traditions of making competition part of the curriculum (Berenson, 2008). For example, courses in dance Lapointe-Crump (2007), ballet (Morris, 2008), poetry (Eastwell, 2007), and music (Ingle, 2001). Sciences also have a history of competition in their respective curricula, such as science poster competitions (Abernathy \& Vineyard, 2001) and design competitions in engineering (Betts, 2002; Matthews \& Spencer, 2001).

On a philosophical level, debate exists as to whether or not competition helps or hinders the educational process. Pharo (2005) notes that generally the same moral criticisms leveled against capitalism tend to be addressed against using competition in the classroom. In other words, if one could moralize capitalism, then one could moralize the use of pitting one student against another in pedagogical contexts. Garcia, Tor, and Gonzalez (2006) advocate that the morality of using competition philosophically is tied to whether the competition has built-in advantages for some students - or whether all have equal access to potentially winning. In other words, competition in education is moral if the playing field is level, but immoral if unfair advantages cause some students typically to win and other typically to lose, with everyone beginning the competition with varying levels of advantage.

Competition appears to have dynamics for various classes of people. For example, gifted students generally seem to handle competition much better than do their peers with less ability (Ozturk \& Debelak, 2008). 
Similarly, Chinese students generally thrive more academically in competition settings when compared to non-Asian students (Shui-fong, Pui-shan, Law, \& Chung, 2004). Non-Asian, immigrants to the United States, particularly, may struggle with competition in educational contexts (Esses, Dovidic, Jackson, \& Armstron, 2001).

Gender is another class where students have shown differences in competition preferences. From relatively early ages in school, competition tends to be viewed differently by boys and girls (Duncan, 2004). Schneider, Woodburn, Toro, and Udvari (2005) report that friendships tend to be more meaningful and deeper for females, which becomes a variable that later may have significant impacts on how competition is viewed in classroom settings. Interpreting matters more personally (Turman, 2007) may be part of the dynamic involved in this regard. Also, Hebl, King, McGuire, and Turchin (2008) report that males and females may not differ, innately, in some educational areas but when the students come to understand that competition has been introduced to the situation as an explicit variable, then males may become more aggressively motivated to perform better than they otherwise might. Some of their empirical research bears this to be the case in learning settings. And finally, Benenson, et al. (2002) report that overall females do not like competition in educational settings as much as boys. That is, apart from whether they perceive themselves as good or poor at the tasks to complete, females tend not to enjoy the thrill of competition to the extent that males generally do.

Moving from the general construct of completion to the more particular focus of competition in business classes, it is apt to appraise how competition affects the learning process for college business students. Certainly, competition is part of the market place into which college students will find job (Mosca, 2008). In order to be successful in most careers, there is some minimal level of competition they will need to navigate politically (Martimort \& Semenov, 2008) and as part of normal business operations in a capitalistic economy (Engle, 2008).

Overall, the research literature reports positive sentiments regarding the use of competition in business classroom settings. Some, such as Wang and Yang (2003) warn that completion may discourage those with lesser abilities, weakening their self-perceived efficacy. They, presumably, will try to win by not losing. Similarly, Chan, and Lam (2008) reported a study where a competitive classroom lowered student's self-efficacy when they engaged in vicarious learning when compared to paired students in non-competitive milieu. However, if competition is presented by faculty in the frame of cooperation, then apparent benefits may be gleaned without some of the unfortunate psychological baggage (Fitch \& Loving, 2007). For example, in a funded project where individual students could earn up to $\$ 1,000$, based on competitive performance in a business class, Umble, Umble, and Artz (2008) reported that student learning was superior when students engaged in competition within the context of cooperative learning and where results depended on completing successfully complex, unstructured projects.

Jameson (2007) reported a case study where he used competition as an integral part of a business education course at Cornell. He found that students differed in how they responded to this protocol along cultural grounds. He summarized: "For the Americans and the Indians, the classroom was a site of intellectual competition-like a sports stadium - where they could demonstrate their knowledge and try to crush other with their unassailable arguments. They loved the give and take of learning as a game. The French students, however, refused to play this game. From their perspective, the combatants were too enthusiastic, overly confident, and undignified" (p. 214).

Roncariati, et al. (2006) reported that inter-group competition improved assessment performance (grades), which they assumed to mean that students learned more from the course than they would have without the introduction of competiton. Fischer (2008) reported that for students who were considered to be highly integrated, competition had a trust-generating effect on them. Widmier, Loe, and Selden (2007) reported that introducing competition to a business education curriculum resulted in differential notations made by prospective employers when students applied for sales jobs at graduation. Borland, Howsen, and Trawick (2006) reported that intercampus competition among business students resulted in overall increased student achievement. Across competitive classroom settings, the effects of fatigue in students (Trent, et. al., 2008) and to what degree they perceive themselves to be ready in facing their competitors (LeMaire, Short, Ross-Stewart, \& Short, 2007) may be oscillating variables that moderate the success of the instructor's endeavors.

The empirical research presently reported in the available literature has focused on outcomes appraisals of students involved with classroom competition. Consequently, we approached the general topic from a different 
vantage point. Namely, we sought to assess how students perceive the completion process. Typically, quantitative research - the type conducted until now and reported in the research literature - asks "what" or "how many" types of questions. Qualitative research, in contrast, tends to ask "why" or "how" types of questions (Johnson \& Christensen 2004). Consequently, we adopted a qualitative research model in order to address the question of how students come to view competition when it is introduced into a required business course. To this end, we elicited participation from a faculty member in the business department who used competition as part of the course design. That is, students were given a semester-long assignment that involved competing with one another as an explicit part of the course requirements. Additionally, the students' overall course grade, in part, was based on how they performed in the competition. Our aim was to understand better the students' perceptions of how they experienced the phenomenon of competition in a required college course.

\section{METHOD}

The present study was designed in the tradition of action research (Mills, 2007). This is a research paradigm that uses one's own classroom in order to conduct an empirical investigation for enhancing future education in one's class as well as benefiting other instructors whose classes have enough similarities to allow reasonable generalization. The development of the blueprint involved a phenomenological study (Flick, 2006) which is an established, subtype of qualitative research. In it, the researcher seeks to understand a phenomenon from the standpoint of the research participants who provide the data. The goal is to report findings that reflect the participants' perspectives regarding the construct being studied (Marshall, \& Rossman, 2006), in this case, graded classroom competition. For purposes of the present study, students understood the construct of competition as being comprised of the following components: (a) two or more parties, (b) the idea of beating someone or outperforming someone, (c) the parties involved are pursing the same objective, and (d) the context requires only one winner.

\section{Participants}

The class studied was a senior-level Administrative Policy and Strategy course at a private, selective, comprehensive university located in the Midwest, enrolling approximately 3,000 students. The class was required of all management majors at the university. There were 32 students enrolled in the course and all agreed to provide interviews for the study. There was no attrition and the course instructor did not have access to the transcripts of the interviews, nor did he conduct any of the interviews. Student ages ranged from 21-24 years of age, all were Caucasian (the student body at this institution had only a $6 \%$ minority population), and 12 of the students were females and 20 were males.

\section{Procedure}

Following the protocol of Firmin (2006), we conducted interviews in two waves. In the first, all participants were interviewed. This provided the broad exposure to all participants with a second wave consisting of interviews with selected students for whom clarification of their initial interviews were warranted or for whom more rich descriptions of their initial replies were helpful. We utilized semi-structured interviews (Seidman, 2006), allowing participants to digress at points where they were able to provide helpful elaborations and elucidate points meaningful to them. Coding the data occurred in between the first and second interview waves, allowing the researchers time for consultation and reflection for how best to utilize the second wave interviews.

Interviews conducted during the last two weeks of the semester, being tape recorded and transcribed for later analysis. An open coding strategy was employed with the interview data. Following Maxwell (2005), we used an inductive method of continually comparing the new transcripts with the previous ones, and highlighting repetitions among key words, phrases, and constructs. Sometimes the categories being coded were collapsed when they contained sufficient overlap and doing had a priori bases. This process also helped to keep the data manageable among all the various transcripts.

Themes were generated from the coding process when they reflected the consensus of most participants. Controversy exists in qualitative research presently regarding the role of theory (Raffanti, 2006). Some (e.g., Silverman \& Marvasti, 2008) advocate that it should be used to interpret findings while other authorities in the field 
(e.g., Glaser, 2003) believe that theory is best used by the reader for interpretation-not the author. We are of the latter, more traditional school of qualitative research. Consequently, our distance from using applying theory in the discussion section of this article is not an oversight. Rather, we are applying a particular paradigm in qualitative research methodology (Creswell, 2007).

Internal validity was enhanced in our study through a number of mechanisms. One was to generate a data trail from the findings to the specific quotes and citations in the participants' transcripts (Daytner, 2006). This provides a check on the research study as readers are able to trace how our findings genuinely reflect the overall sentiments of the research participants. Additionally, member checking (Bailey, 2007) was applied. This entails sampling individuals from the participants' interview, asking them to provide feedback on the results we propose. All individuals sampled indicated our findings aptly reflected the general perspectives they held. Third, internal validity was enhanced by employing the use of a qualitative researcher who was outside of the actual research project (Silverman, 2005). He provided assistance to ensure that what we proposed to find both was grounded adequately in the data collected and also followed apt qualitative protocol in reaching the conclusions.

Saturation occurred during the interview process. This means that we reached a level where adding more participants was not providing significant levels of new information. In qualitative research, a sample of, say, 62 individuals is not necessarily better than, say, 32 individuals - if people are essentially repeating the same constructs in the interviews. Using models by qualitative researchers such as Guest, Bunce, and Johnson (2006), we believe that the sample size used in the present study was adequate for the intended purposes.

Sometimes when presenting the findings of a qualitative research study, we use plentiful quotes from the research participants in the journal article. This is general protocol for qualitative research and it provides the reader with rich descriptions of the how the participants expressed their sentiments (Holliday, 2007). However, we deliberately are choosing not to follow this practice for the present article. The class obviously knew that they were being studied and the students in the course, as seniors, were familiar with one another. We believe that this particular group of students would be more comfortable having been part of the study, if their specific comments were not revealed. Additionally, the course professor may be providing references for these students in the years to come, so he will never be able to identify any particular quote with any student. In short, in the spirit of ethical sensitivity (Berg, 2007), we are choosing the present protocol in presenting the research findings.

\section{RESULTS}

Four over-arching themes emerged from the transcripts. One was that students showed both cognitive and affective self-insight into how they perceive themselves competing in class. Second, a circumstantial nature of student competitiveness emerged, particularly relating to how students understood their chances of winning in the competition. Third, gender differences were evident in how the students perceived the classroom competition exercise. Fourth, relational aspects of competition were realized, including sympathy feelings for others in the class and how students' own behaviors were influenced by the responses of cohorts. Each theme will be discussed below.

\section{Cognitive And Affective Insight}

First, students showed significant self-insight into how they perceive themselves competing. This occurred on both the cognitive and affective domains. In describing their thinking processes, students articulated elements: (1) They acquired a mindset of having to win; (2) Beating the other person was conceptualized as success in this classroom context; (3) They described ways to outwit or out strategize the opposition; (4) They sought means to exploit weaknesses or to counteract their opponent's potential moves; and (5) They analyzed what they did in preparation for their next competition.

Affectively, students showed self-insight as they related four components of their feelings during competition. On the negative side, they reported feeling nervous/anxious, frustrated/stressed, and angry/aggressive. However, they also described the affect of adrenaline rush/excited/satisfaction. It appeared, however, that the negative aspects of their emotional experience were counterbalanced by the passionate feelings, bringing euphoria. 
That is, even though students reported feeling greater numbers of negative emotions, the power of the excitement seemed to balance or, more likely, over-balance the negative feelings they report.

\section{Circumstantial Nature Of Student Competitiveness}

The second predominate theme we found in the interviews relates to the circumstantial nature of student competitiveness. With relative consistency, students reported avoiding competitive situations where they did not believe chances were good that they would win. Conversely, they tended to involve themselves in situations where success was perceived as possible or likely. In short, they described a toggle process of heightened alertness to maintaining risk management, attempting to keep the risks moderated in their own respective favor.

In addition, students told us that they tended to become non-competitive or less-competitive in circumstances where the potential rewards were not tangible or where delay of gratification was a factor. Evidently, competition is strongest for our sample of students when the enjoyment of rewards was more concrete than when it is abstract and when it is more immediate than potentially distant. With this, students indicated that they tended to gravitate towards competition when the potential reward is valuable to them. Of course, an award's worth is relative to the individual. However, when the outcome possessed such personal significance, students tended to begin thinking in competitive terms in order to achieve their objectives.

Unanimously, participants agreed that consequences were an equal or greater motivator for competition with rewards. That is, if students feared loss or hardship, then the same competition drive was activated as it did when there were potential gains to be won. Interestingly, most students also told us that the graver the consequences, the more effort they put into striving to win during the competition. In other words, fearing consequences was relatively more cogent than hope for potential gain.

About three-fourths of the students we interviewed indicated that they expected to win the majority of the time they compete. This finding needs to be kept in the context, however, that students tend to self-select competitive milieu. About two-thirds of the students indicated that being prepared was the most salient factor that provided confidence in competition. With one exception, all the students identified themselves as being internally motivated, rather than depending on extrinsic factors in their striving to win.

\section{Gender Differences}

The third predominate theme we found in the interviews relates to gender differences in student competition. All of the males in our study indicated that they were relatively competitive in sports. However, this was said to be true only true when competing with other males. That is, the males in the study shared their perspectives that females are less skilled athletically and what they frequently referred to as "fragile." Women reported disliking when males belittle them regarding their athletic ability, but nonetheless, they also reported being less competitive when with males. More specifically, they reported being more competitive in sports when they were with females only. The female participants indicated feeling more similar to other females when competing athletically and their progress and accomplishments are more easily measurable.

In all non-sport areas, however, such as academics-females and males in our research sample indicated being equally competitive. That is, both males and females reported egalitarian sentiments when competing with both genders. The competition was said to be open and without concern for stereotype or other socialized factors. This, of course, is self-report interview data relating to how they think of themselves - not necessarily the way that the male and female students behave in competitive settings.

\section{Relational Aspects Of Student Competition}

The fourth predominate theme we found in the interviews relates to relational aspects of competition. Three particular sub-findings comprise this theme. One is the role of students' developmental years. Peers, sports, and family members were said to have played the most significant roles in the development of a competitive spirit with our students. Friends often provided significant role models as also did the people to whom our students won 
or lost. Peer reactions to events during critical developmental years seem to have left an indelible impression on many of our students. Sports had an obvious effect, including whether they played on winning or losing teams. Family members provided both role models for competition, but also a kind of informal coaching. Sometimes a father, grandfather, mother, or other key person egged-on a competitive spirit and fostered it in the child. The role of the family seems to be predominately in the student's developmental years, however, as they did not report consistent data regarding the present role of family members regarding current competing tendencies.

A second sub-finding relating to the relational aspects of competition in students was sympathy. All but a few students reported that they regularly felt sympathetic for cohorts when the peers lost. Sometimes students used the word empathy - but when queried more carefully in the interviews - the wordsmith intention they provided was actually sympathy. The two mediating factors that tended to muster sympathetic feelings in most circumstances were the relationship the student had with his/her competitor and also the competitor's attitude (e.g., cockiness by the competitor resulted in less sympathy felt by the participant).

A final sub-finding relating to the relational aspects of competition in students related to how the contests tended to cause students to relate to others in general - even if the other people had no relationship to the competition at hand. For example, students frequently reported that they were more moody around others when they were in class-competitive mode. They did not wish to be that way around others, necessarily, and sometimes the reactions they described having around peers may have been somewhat subconscious. Competition also caused students to be more driven around their friends and acquaintances (not in the class). For some, the descriptions they used almost seemed to border on obsessiveness or compulsiveness at times. The point is that competition was said to affect student relationships, both with whom the participants were competing, but also sometimes those outside the circle of the classroom contest.

\section{DISCUSSION}

The results of the present study showed congruency with some previously reviewed literature regarding student competitions. A most prominent consistency regarded gender differences. Hebl, et al. (2008) reported that males may not differ, innately, in some educational areas but when the students come to understand that competition has been introduced into the situations, then males may become more aggressive, being more motivated to win than they likely would have been otherwise. Further, Benenson, et al. (2002) reported that, overall, females did not like competition in educational settings as did males. The findings from the present study are generally congruent with the conclusions from these previous studies. Females in our present study reported that they generally approached the competition activities with egalitarian mindsets.

Fitch and Loving (2007) had reported that competition could be conducted in university business courses without presumed psychological baggage if competition is presented in terms of competition. The present study seemingly advanced this model, indicating that students approached the classroom competition and completed the process without reported harm or extensive frustrations. There was some moodiness indicated and they were strained somewhat with non-classroom relationships - but nothing was reported to an extreme that might suggest undue psychological issues for the participants.

The results from the study are highly consistent with social psychology researching regarding potential loss and gains (Feldman, 2001). Particularly, people in general are more guarded about what they might lose - even if it is a relatively small amount - than they are about what they might potentially gain - even if the potential gain is larger than the potential loss. This social conservative nature was seen among our participants. That is, fearing consequences was relatively more cogent than hope for potential gain.

Similarly, the results are relatively consistent with classical learning theory (Lefrancois, 2006). Both animals and humans consistently have been shown to work differentially, depending on the level of rewards offered for engaging in assigned behavior. Students in the study told us that they tended to become non-competitive or lesscompetitive in circumstances where the potential rewards were not tangible or where delay of gratification was a factor. Evidently, competition is strongest for our sample of students when the enjoyment of rewards was more concrete than when it is abstract and when it is more immediate than potentially distant. With this, students 
indicated that they tended to gravitate towards competition when the potential reward is valuable to them. The participants' behaviors follow a general behaviorist model where potential rewards and punishments have significant influences over potential learning outcomes.

Students in the study showed behaviors consistent with research findings in cognitive science (Reisberg, 1997). Generally, humans respond to their environments in reflexive manners. That is, they frame their situations, take actions, then re-evaluate their subsequent actions, based on the outcomes of previous outcomes. Participants in the present study acted in accordance with these cognitive science principles. They demonstrated reflexive natures, deciding with whom to compete and in what circumstances it most likely would be to their advantages in doing so. In short, they showed behavior patterns that extended far beyond mere stimulus-response patterns. Rather, they used cognitive behavioral patterns more consistent with the brain's executive functioning and processing modalities.

\section{LIMITATIONS AND FUTURE RESEARCH}

One of the hallmarks of a quality research study is the explicit identification of its potential limitations (Price, 2004). In that light, we discuss them here-as well as potential future research that will advance our understanding of student competition phenomenology. Consistent with general principles of classroom action research (Johnson, 2008), much of the limitation related to the present study is embedded in the research paradigm of qualitative inquiry. Particularly, qualitative research is always context-specific (Niaz, 2006), focusing on the perspectives of the participants selected from the criterion-related classroom (Ditranto \& Silverstein, 2006). Consequently, the present research findings are tied to the students in the class that we assessed.

Nonetheless, action research has significant potential of heuristic value for future researchers (Moss, 2003). In that light, we believe that the present study will be valuable to future researchers, building on the foundation we have established with the present article. Studying competition's effects across multiple domains and multiple educational contexts will help provide a broader and clearer picture of how college students view the construct of business course competition. Consistent with Schafer (2001), as this qualitative studied is replicated across various milieu, external validity will solidify.

As previously noted, the students in the present course being studied were Caucasian. Consequently, future studies should study minority students, comparing the present findings with students from various ethnic backgrounds. Further, the students from the present study attended a selective, comprehensive, Midwest university. Future researchers should draw samples from colleges such as open-enrollment, state universities, community colleges, elite, and inner-city contexts. Comparisons among how students who are enrolled in a variety of universities perceive the competition construct would provide both enlightening and useful for business instructors. In sum, studies across multiple domains in this area will help provide ultimate answers to external validity questions (Mook, 1989; Morse, Barrett, Mayan, Olson, \& Spiers, 2002).

In sum, believe that these findings are useful for university business professors for better understanding their students when using competition as a pedagogical strategy. That is, as instructors utilize competitive activities in their classrooms and prepare students for a very competitive business world after college graduation-instructors can better strategize in accomplishing their student learning aims. Understanding competition from theoretical, corporate world, and student perspectives can help business educators to map successful academic experiences for students preparing for competitive business careers. Future instructors of business courses are encouraged continue this type of classroom assessment, adding to the broader knowledge in this important field (Green, 2001).

\section{AUTHOR INFORMATION}

Michael W. Firmin earned his Ph.D. from Syracuse University. He serves as professor and chair of the psychology department at Cedarville University in Cedarville, $\mathrm{OH}$. Firmin has more than 60 peer-reviewed publications and over 100 papers presented at national research conferences. He is a licensed psychologist in the state of Ohio. Firmin serves as editor for the Journal of Ethnographic \& Qualitative Research and directs the national Ethnographic \& Qualitative Research Conference, now in its 21st annual year. 
Jennifer Evens Lucius is an Executive Assistant at ghSMART. She is responsible for providing support to two Principals, managing projects, scheduling assessments, invoicing, meeting planning, and travel. Prior to joining ghSMART, Jennifer worked as an Executive Assistant / Project Coordinator, supporting senior leaders in leading companies in organizational consulting. Jennifer holds an M.Ed. in Human Resources and Organizational Development from the University of Georgia and a B.A. in Psychology from Cedarville University.

Dr. Sharon Johnson is Professor of Management and Director of Academic Research and Assessment at Charleston Southern University. He also serves as an adjunct faculty in the DBA program at Anderson University and the Taylor University MBA program. Dr. Johnson received his DBA in management from Florida State University in 1978. Dr. Johnson's work has been published in a wide variety of academic, trade, and Christian publications, served as a consultant to a variety of public and private organizations, and has made many presentations at academic meetings. He serves as Senior Editor of Publications for the Christian Business Faculty Association. His current scholarly focus is on the nature and impact of interpersonal competition.

\section{REFERENCES}

1. Abernathy, T., \& Vineyard, R. (2001). Academic competitions in science. Clearing House, 74, 269-276.

2. Adie, J., Duda, J., \& Ntoumanis, N. (2008). Achievement goals, competition appraisals, and the psychological and emotional welfare of sport participants. Journal of Sport \& Exercise Psychology, 30, 302-322.

3. $\quad$ Bailey, C. A. (2007). A guide to qualitative field research $\left(2^{\text {nd }}\right.$ ed.). Thousand Oaks, CA: Sage.

4. Beneson, J., Roy, R., Waite, A., Goldbaum, S., Linders, L, et al. (2002). Greater discomfort as a proximate cause of sex differences in competition. Merrill-Palmer Quarterly, 48, 225-247.

5. Berenson, G. (2008). Competitions, recitals and auditions. American Music Teacher, 57, 4-5.

6. Berg, B. L. (2007). Qualitative research methods for the social sciences $\left(6^{\text {th }}\right.$ ed.). Boston: Pearson.

7. Betts, K. S. (2002). Solar power competition. Environmental Science \& Technology, 36, 450-451.

8. Borland, M., Howsend, R., \& Trawick, M. (2006). Intra-school competition and student achievement. Applied Economics, 14, 1641-1647.

9. Chan, J., \& Lam, S. (2008). Effects of competition on students' self-efficacy in vicarious learning, Journal of Educational Psychology, 78, 95-108.

10. Cresswell, J. W. (2007). Qualitative inquiry \& research design: Choosing among five approaches $\left(2^{\text {nd }}\right.$ ed.). Thousand Oaks, CA: Sage.

11. Daytner, K. (2006). Validity in qualitative research: Applications and safeguards. Paper presented at the $18^{\text {th }}$ Annual Ethnographic \& Qualitative Research in Education Conference, Cedarville, OH.

12. Ditrano, C. J., \& Silverstein, L. B. (2006). Listening to parents' voices: Participatory Action Research in the Schools. Professional Psychology: Research and Practice, 37, 359-366.

13. Duncan, N. (2004). It's important to be nice, but it's nicer to be important: Girls, popularity, and sexual competition. Sex Education, 4, 137-152.

14. Eastwell, P. (2007). International science poetry competition. Teaching Science, 53, 49-50.

15. Engle, P. (2008). Benchmarking competition. Industrial Engineer, 40, 20-21.

16. Esses, V., Dovidio, J., Jackson, L., \& Armstron, T. (2001). Journal of Social Sciences, 57, 389-413.

17. Feldman, R. S. (2001). Social Psychology ( $3^{\text {rd }}$ ed.). Upper Saddle River, NJ: Prentice Hall.

18. Firmin, M. (2006). Using interview waves in phenomenological qualitative research. In P. Brewer \& M. Firmin (Eds.). Ethnographic \& qualitative research in education (pp. 175-181). New Castle, UK: Cambridge Scholars Press.

19. Fisher, J. (2008). Is competition good for trust? Cross-country evidence using micro-data. Economics Letters, 100, 56-59.

20. Fitch, F., \& Loving, G. (2007). Competition and cooperation: Evil twins or fated lovers? Philosophical Studies in Education, 38, 83-93.

21. Flick, U. (2006). An introduction to qualitative research ( $3^{\text {rd }}$ ed.). Thousand Oaks, CA: Sage.

22. Garcia, S., Tor, A., Gonzalez, R. (2006). Ranks and rivals: A theory of competition. Personality \& Social Psychology Bulletin, 32, 870-982.

23. Glaser, B. (2003). Conceptualization contrasted with description. Mill Valley, CA: Sociology Press.

24. Green, E. (2001). Can qualitative research produce reliable qualitative findings? Field Methods, 13, 3-19. 
25. Guest, G., Bunce, A., \& Johnson, L. (2006). How many interviews are enough? An experiment with data saturation and variability. Field Methods, 18, 59-82.

26. Hebl, M., King, E., McGuire, J., \& Turchin, M. (2008). The grapefruit race: Demonstrating the influence of competition on gender differences in intimacy. Teaching of Psychology, 35, 18-21.

27. Holliday, A. (2007). Doing and writing qualitative research ( $2^{\text {nd }} \mathrm{ed}$.). Thousand Oaks, CA: Sage.

28. Ingle, G. (2001). On competition and celebration. American Music Teacher, 50, 1-2.

29. Jameson, D. (2007). Competition in the classroom. Business Communication Quarterly, 70, $212-216$.

30. Johnson, A. P. (2008). A short guide to action research ( $3^{\text {rd }}$ ed.). Boston: Allyn \& Bacon.

31. Johnson, B., \& Christensen, L. (2004). Educational research: Quantitative, qualitative, and mixed approaches ( $2^{\text {nd }}$ ed.). Boston: Allyn \& Bacon.

32. Lapointe-Crump, J. (2007). Competition and dance education. The Journal of Physical Education, Recreation, \& Dance. 78, 4-9.

33. Lefrancois, G. (2006). Theories of human learning ( $5^{\text {th }}$ ed.). Belmont, CA: Wadsworth.

34. LeMaire, J., Short, S. E., Ross-Stewart, L., \& Short, M. (2007). The effect of uniform color on athletes' readiness for competition and perception of opponents' attributes. Journal of Sport \& Exercise Psychology, 29, 180-181.

35. Mansoor, N. (2006). Can findings of qualitative research in education be generalized? Quality and Quantity, 41, 429-445.

36. Marshall, C., Rossman, G. (2006). Designing qualitative research (4 ${ }^{\text {th }}$ ed.). Thousand Oaks, CA: Sage.

37. Martimort, D., Semenov, A. (2008). The informational effecs of competition and collusion in legislative politics. Journal of Public Economics, 92, 1541-1563.

38. Mattews, T. W., \& Spencer, R. R. (2001). An autonomous race car design competition. IEEE Transactions on Education, 44, 215-216.

39. Maxwell, J. A. (2005). Qualitative research design ( $2^{\text {nd }}$ ed.). Thousand Oaks, CA: Sage.

40. Morris, G. (2008). Artistry or mere technique? The value of ballet competition. Research in Dance Design, 9, 39-54.

41. Mosca, M. (2008). On the origins of the concept of natural monopoly: Economics of scale and competition. Journal of the History of Economic Thought, 15, 317-353.

42. Mills, G. E. (2007). Action researcher ( $3^{\text {rd }}$ ed.). Upper Saddle River, NJ: Prentice Hall.

43. Mook, D. G. (1989). The myth of external validity. In L. W. Poon, D. C. Rubin, \& B. A. Wilson (Eds.). Everyday cognition in adulthood and late life (pp. 25-43). New York: Cambridge University Press.

44. Morse, J., Barrett, M., Mayan, M., Olson, K., \& Spiers, J. (2002). Verification strategies for establishing reliability and validity in qualitative research. International Journal of Qualitative Research, 1(2).

Retrieved from http://www.ualberta.ca/ ijqm

45. Moss, P. A. (2003). REconceptualizing validity for classroom assessment. Educational Measurement, 22 , 13-25.

46. Ozturk, M., \& Debelak, C. (2008). Affective benefits from academic competitions for middle school gifted students. Gifted Child Quarterly, 31, 48-54.

47. Price, J. (2004). Research limitations and the necessity of reporting them. American Journal of Health Education, 35, 66-67.

48. Pharo, P. (2005). The ethics of competition. International Social Science Journal, 57, 445-455.

49. Raffanti, M. (2006). Grounded theory in educational research: Exploring the concept of "groundedness." In M. Firmin \& P. Brewer (Ed.). Ethnographic \& qualitative research in education Vol 2. (pp. 61-74). New Castle, UK: Cambridge Scholars Press.

50. Reisberg, D. (1997). Cognition. New York: W.W. Norton.

51. Romanello, T. (2005). Collaborative competition? A great way to teach and motivate. Physics Teacher, 43, 76-78.

52. Roncarati, M., Brassey, A., Bridges, P., Creaby, C., Holder, G., et al. (2006). Teaching Business \& Economics, 10, 32-34.

53. Schafer, W. D. (2001). Replication: A design principal for field research. Practical Assessment, Research, \& Evaluation, 7(15). Retrieved from http://PAREonline.net.

54. Schneirder, B., Woodburn, S., Toro, M., Udvari, S. (2005). Cultural and gender differences in the implications of competition for early adolescent friendship. Merrill-Palmer Quarterly, 51, 163-191. 
55. Scott, W., Loe, T., \& Selden, G. (2007). Using role-play competition to teach selling skills and teamwork. Marketing Education Review, 17, 69-78.

56. Seidman, I. (2006). Interviewing as qualitative research ( $3^{\text {rd }}$ ed.). New York: Teachers College Press.

57. Shui-fong, L., Pui-shan, Y., Law, J., \& Cheung, R. (2004). The effects of competition on achievement in Chinese classrooms. British Journal of Educational Psychology, 74, 281-296.

58. Silverman, D. (2005). Doing qualitative research $\left(2^{\text {nd }}\right.$ ed.). Thousand Oaks, CA: Sage.

59. Silverman, D., \& Marvasti, A. (2008). Doing qualitative research: A comprehensive guide. Thousand Oaks, CA: Sage.

60. Singleton, E. (2003). Rules? Relationships? A feminist analysis of competition and fair play in physical education. Quest, 55, 193-209.

61. Trent, J., Johnson, B., Battista, R., Wright, Dodge, C., et al. (2008). Perception of fatigue during simulated competition. Medicine \& Science in Sports \& Exercise, 40, 381-385.

62. Truman, P. D. (2007). The influence of sex, context, and performance on high school basketball coaches' use o regret messages during competition. Communication Education, 56, 333-353.

63. Umble, E., Umble, M., \& Kendall, A. (2008). Enhancing undergraduates' capabilities through teambuilding competitions: The Edward Jones Challenge. Journal of Innovative Education, 6, 1-27.

64. Wang, H., \& Yang, B. (2003). Why competition may discourage students from learning? A behavioral economic analysis. Education Economics, 11, 117-129.

\section{NOTES}

